Available online on 15.11.2020 at http://ujpr.org
Universal Journal of Pharmaceutical Research
An International Peer Reviewed Journal
Open access to Pharmaceutical research

\title{
SEROPREVALENCE OF DENGUE FEVER VIRUS AMONG SUSPECTED PATIENTS IN TAIZ GOVERNORATE-YEMEN
}

\section{Qais Yusuf Abdullah ${ }^{1}\left(\mathbb{D}\right.$, Mohammed Farhan Al-Helali ${ }^{1}{ }^{1}$, Anes Al-Mahbashi ${ }^{1}(\mathbb{D}$, Sameh Taha} Qaaed $^{1}\left(\mathbb{D}\right.$, Wadhah Hassan Edrees ${ }^{2,3 *}$ (D)

${ }^{I}$ Biology Department, Microbiology Section, Faculty of Science, Sana'a University, Yemen.

${ }^{2}$ Medical Laboratory Department, Faculty of Medical Sciences, Al-Razi University, Yemen.

${ }^{3}$ Medical Microbiology Department, Faculty of Applied Sciences, Hajjah University, Yemen.

\section{ABSTRACT}

Background: Dengue Fever virus (DENV) considers one of the most important mosquito-borne viral diseases in the world and it is endemic in more than 100 countries.

Objective: This study aimed to determine the seroprevalence of DENV infection among suspected patients and to investigate some associated risk factors with dengue fever infection in Taiz governorate, Yemen.

Methods: This study was cross-sectional, descriptive, and experimental, combining the use of a structured questionnaire and analysis of serum samples obtained from 300 suspected patients attending at many hospital and clinic centers in Taiz during the period from July to November 2016. The serum samples were tested for anti-dengue immunoglobulin (IgM) and (IgG) by Enzyme-linked Immunosorbent Assay (ELIZA).

Results: Out of 300 suspected febrile cases, it was found that 49(16.3\%), 68(22.7\%), and 17(5.7\%) cases were showed positive for the IgM, IgG, and both IgM and IgG antibodies, respectively, while $166(55.3 \%)$ cases were negative. The incidence rate was more in males than in females. The most affected age groups with dengue fever infection were (21-30) years. Dengue Fever was more frequent among patients coming from the urban area, having secondary school, and low-income status people. Also, there was statistical significant between DENV infections with a place of residency and gender $(P<0.05)$ and not-statistical significance between DENV infections and other factors $(P>0.05)$.

Conclusion: Taiz governorate become one of the endemic governorates in Yemen particularly the Taiz city which should be brought to the attention of public health authorities

Keywords: Dengue fever virus, IgG, IgM, Seroprevalence, Taiz governorate, Yemen.

Article Info: Received 25 August 2020; Revised 15 September; Accepted 30 October, Available online 15 November 2020

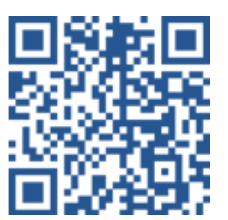

Cite this article-

Abdullah QY, Al-Helali MF, Al-Mahbashi A, Qaaed ST, Edrees WH. Seroprevalence of dengue fever virus among suspected patients in Taiz Governorate-Yemen. Universal Journal of Pharmaceutical Research 2020; 5(5):21-26.

DOI: https://doi.org/10.22270/ujpr.v5i5.482

Address for Correspondence

Dr. Wadhah Hassan Edrees, Medical Laboratory Department, Faculty of Medical Sciences, Al-Razi University, Yemen. Medical Microbiology Department, Faculty of Applied Sciences, Hajjah University, Yemen. Tel: +967-771673230, E-mail: wadah.edrees@alraziuni.edu.ye

\section{INTRODUCTION}

Dengue Fever virus (DENV) is one of the significant commonest mosquito-borne viral diseases in the world and it is endemic in more than 100 countries that estimated about 100 million infected cases and about 25,000 deaths per year worldwide ${ }^{1}$. DENV is an enveloped, positive-sense, single-stranded RNA genome that belongs to the family Flaviviridae, genus Flavivirus ${ }^{2}$. One of the four serotypes of dengue viruses (DENV1-4) able to cause dengue fever. These types of viruses are transmitted by an infected females of Aedes egypti (major vector) and Aedes albopictus during biting the human host for obtained the meal of blood $^{3}$. The virus transmission from person-to-person by the direct method has not been documented. Although few reports have been illustrated about the route of DENV transmission through exposure to DENV-infected organs, blood, or other tissues from solid organ transplants, blood transfusions, or bone marrow transplants ${ }^{4,5}$. Dengue virus causes primary and secondary infections. Primary infection is an acute feverish illness known as Dengue Fever (DF) which mostly eliminates around seven days by a composite 
immune response, while the secondary infection is additional rigorous and causes Dengue Hemorrhagic Fever (DHF) or Dengue Shock Syndrome (DSS $)^{6,7}$.The majority of deaths that result from dengue infection result from Dengue Hemorrhagic Fever (DHF) and Dengue Shock Syndrome (DSS) ${ }^{8}$. In Yemen, the early first recorded of dengue-like epidemics in Aden was reported by Hirsch between 1870 and 1873 years ${ }^{9}$. Also, the prevalence of dengue fever was $98 \%$ of the studied population recorded in Al-Hudidah governorate in $1954^{10}$. After that dengue fever became an epidemic in the coastal planes of the Tehama (Hudidah), then outbreaks increased since 2005 and the disease has spread to new governorates ${ }^{11}$.
All three dengue viral serortyp1-3 were reported in Yemen but type 2 of the Dengue virus was the most predominant serotype in Yemen ${ }^{12}$. Interestingly DENV serotype 4 was identified and confirmed the first time in Al-Hudidah-Yemen by Alahdal et al., ${ }^{13}$. In the Taiz governorate, the infection rate varied from year to year. Recently, $\mathrm{WHO}^{14}$ documented an extreme prevalence in cases of dengue fever in Taiz governorate were reached to1328 suspected cases compared with last years. But the seroprevelance of DENV is not well documented so far. Therefore, this work aimed to evaluate the seroprevalence of dengue fever and to reveal some possible risk factors associated with DENV infection in Taiz governorate, Yemen.

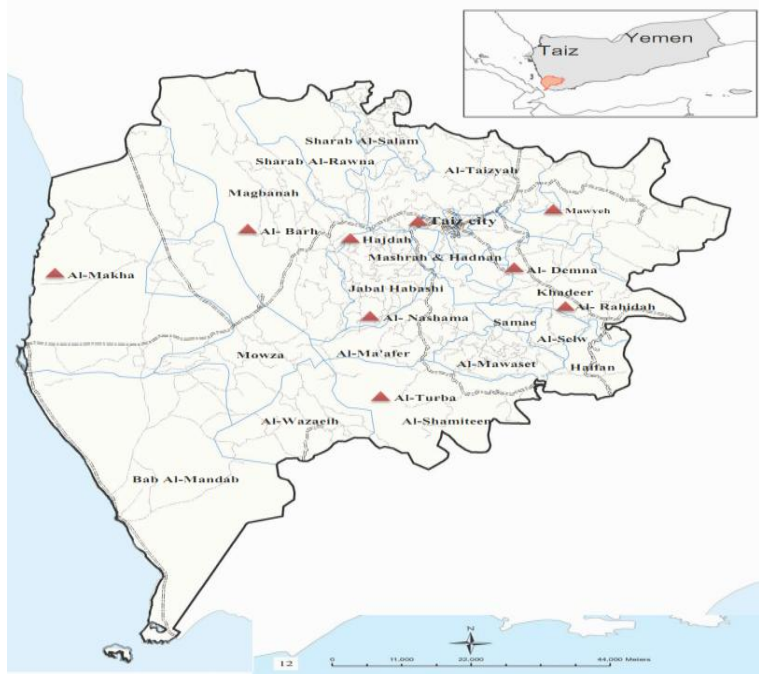

Figure 1: Map of Yemen and Taiz governorate.

\section{SUBJECTS AND METHODS}

\section{Study area}

In the place of southwestern of Yemen, Taiz governorate locatesin East of GMT. It is the thirdlargest governorate in Yemen and its population is $2,393,425$ according to the census of the 2004 year $^{15}$. Administratively, Taiz is among the largest governorates as it includes 23 districts in its frame. Taizclimate is featuring by diversity and the average temperature is up $\left(21^{\circ} \mathrm{C}\right)$. The rain falls on all parts of the governorate in the summer while in some districts in the winter ${ }^{16}$.

\section{Study design}

This is a cross-sectional, descriptive was conducted from July to November 2016, performed on suspected patients suffering undifferentiated fever (age range, 1 to 65 years) attending many hospitals and health centers at nine main locations in the Taiz governorate, which most patients coming seeking medical care.

\section{Ethical approval}

This study was approved by the Ethical Review Committee from the Department of Biology, Faculty of Science, Sana'a University.

\section{Data collection}

A structured questionnaire was intended to collect required data from suspected patients according to socio-demographics and risk-related data. The questionnaire was filled for each participant via face-to-face interview by a researcher to avoid any misunderstanding and confirm the accurate collection of data properly.

\section{Sample collection}

About $5 \mathrm{~mL}$ of blood specimen was collected from 300 suspected patients suffering undifferentiated fever by venipuncture and immediately transferred into a sterile anticoagulant-free sterile bottle for clotting. The clotted blood specimen was centrifuged (3000 rpm, $5 \mathrm{~min}$ ), and the serum (the supernatant) was put in separate Eppendrof tubes with a specific study number (SNO) transferred inside a cooling box and stored at $-20^{\circ} \mathrm{C}$ until required for use.

\section{Serological Assay}

Serum samples were examined for DENV-specific IgG and IgM antibodies by using IgG and IgM DRG Immunodiagnostic Kits(GmbH Germany) that were performed by Enzyme-Linked Immunosorbent Assay (ELISA)(Absorbance Microplate Reader/ELIZAIRE96,SFRI, French) ${ }^{17}$.

\section{Statistical analysis}

The obtained results were analyzed by using the version 18.0 SPSS (Statistical Package for Social Science). A significant difference between the proportions and the groups or variables was determined by Chi-square test ( $\geq 3.9$ considered significant) and $P$ value $(<0.05$ considered significant). 
Table 1: Characteristics of study cases.

\begin{tabular}{llcclc}
\hline \multicolumn{2}{c}{ Variable } & $\begin{array}{c}\text { Number } \\
(\mathbf{\%})\end{array}$ & \multicolumn{2}{c}{ Variable } & $\begin{array}{c}\text { Number } \\
(\mathbf{\%})\end{array}$ \\
\hline \multirow{2}{*}{ Gender } & Male & $202(67.3)$ & & Illiterate & $46(15.3)$ \\
& Female & $98(32.7)$ & Education & Primary & $56(18.7)$ \\
& $1-10$ & $24(8)$ & level & Secondary & $113(37.7)$ \\
\multirow{4}{*}{ Age } & $11-20$ & $58(19.3)$ & & University & $85(28.3)$ \\
& $21-30$ & $105(35)$ & Income & Low Status & $160(53.3)$ \\
& $31-40$ & $64(21.3)$ & Status & Med Status & $118(39.3)$ \\
& $41-50$ & $29(9.7)$ & & High Status & $22(7.3)$ \\
\multirow{6}{*}{ Residence } & $>50$ & $20(6.7)$ & & & \\
& Rural & $105(35)$ & & & \\
& Urban & $195(65)$ & & & \\
\hline
\end{tabular}

Table 2: Distributions of anti-DENV with socio-demographical characteristic of the suspected patients.

\begin{tabular}{|c|c|c|c|c|c|c|c|c|}
\hline \multirow{2}{*}{ Variables } & & \multirow{2}{*}{$\begin{array}{c}\begin{array}{c}\text { Number of } \\
\text { cases }\end{array} \\
\text { No. }(\%) \\
\end{array}$} & \multicolumn{2}{|c|}{ IgM positive } & \multicolumn{2}{|c|}{ IgG positive } & \multicolumn{2}{|c|}{ IgM and IgG positive } \\
\hline & & & No. $(\%)$ & $P$-value & No. $(\%)$ & $P$ - value & No. $(\%)$ & $P$ - value \\
\hline Gender & $\begin{array}{c}\text { Male } \\
\text { Female }\end{array}$ & $\begin{array}{c}202(67.3) \\
98(32.7)\end{array}$ & $\begin{array}{l}39(19.3) \\
10(10.2)\end{array}$ & 0.04 & $\begin{array}{l}53(26.2) \\
15(15.3)\end{array}$ & 0.03 & $\begin{array}{c}14(6.9) \\
3(3.1) \\
\end{array}$ & 0.2 \\
\hline $\begin{array}{l}\text { Age } \\
\text { (years) }\end{array}$ & $\begin{array}{c}1-10 \\
11-20 \\
21-30 \\
31-40 \\
41-50 \\
>50\end{array}$ & $\begin{array}{c}24(8) \\
58(19.3) \\
105(35) \\
64(21.3) \\
29(9.7) \\
20(6.7) \\
\end{array}$ & $\begin{array}{c}3(12.5) \\
9(15.5) \\
22(21) \\
9(14.1) \\
4(13.8) \\
2(10) \\
\end{array}$ & 0.7 & $\begin{array}{c}4(16.7) \\
12(20.7) \\
29(27.6) \\
14(21.9) \\
6(20.7) \\
3(15) \\
\end{array}$ & 0.7 & $\begin{array}{c}1(4.2) \\
3(5.2) \\
8(7.6) \\
4(6.3) \\
1(3.4) \\
0(0) \\
\end{array}$ & 0.8 \\
\hline Residence & $\begin{array}{c}\text { Rural } \\
\text { Urban } \\
\end{array}$ & $\begin{array}{l}105(35) \\
195(65) \\
\end{array}$ & $\begin{array}{l}11(10.5) \\
38(19.5) \\
\end{array}$ & 0.04 & $\begin{array}{l}17(16.2) \\
51(26.2) \\
\end{array}$ & 0.04 & $\begin{array}{c}1(1) \\
16(8.2) \\
\end{array}$ & 0.01 \\
\hline $\begin{array}{l}\text { Education } \\
\text { level }\end{array}$ & $\begin{array}{c}\text { Illiterate } \\
\text { Primary } \\
\text { Secondary } \\
\text { University }\end{array}$ & $\begin{array}{c}46(15.3) \\
56(18.7) \\
113(37.7) \\
85(28.3)\end{array}$ & $\begin{array}{c}5(10.9) \\
8(14.3) \\
22(19.5) \\
14(16.5)\end{array}$ & 0.6 & $\begin{array}{c}7(15.2) \\
11(19.6) \\
31(27.4) \\
19(22.4)\end{array}$ & 0.6 & $\begin{array}{l}2(4.3) \\
3(4.5) \\
7(6.2) \\
5(4.8)\end{array}$ & 0.9 \\
\hline $\begin{array}{l}\text { Income } \\
\text { Status }\end{array}$ & $\begin{array}{l}\text { Low } \\
\text { Med } \\
\text { High }\end{array}$ & $\begin{array}{c}160(53.3) \\
118(39.3) \\
22(7.3)\end{array}$ & $\begin{array}{c}30(18.8) \\
17(14.4) \\
2(9.1)\end{array}$ & 0.4 & $\begin{array}{c}41 \text { (25.6) } \\
25(21.2) \\
2(9.1)\end{array}$ & 0.2 & $\begin{array}{c}10(6.3) \\
7(5.9) \\
0(0)\end{array}$ & 0.4 \\
\hline
\end{tabular}

$\chi^{2}$ Chi-square $\geq 3.8 ; P<0.05$ (significant)

\section{RESULTS}

In a total of 300 participants enrolled in this study, 202 $(67.3 \%)$ were males and $98(32.7 \%)$ were females. The highest participant groups in the present study were patients aged between (21-30) years with an average of $105(35 \%)$. Most suspected patients 195 (65\%) were living in urban areas. The suspected patients with secondary education levels were more than the third $113(37.7 \%)$ of the total population in this study. On the other hand, more than half of the respondents 160 $(53.3 \%)$ were of low-income status (Table 1). Out of 300 suspected febrile cases, $49(16.3 \%)$ showed positive results for the IgM antibodies (acute infection) and 68 cases $(22.7 \%)$ were positive for the $\mathrm{IgG}$ antibodies (chronic infection), and 17 cases $(5.7 \%)$ were positive for both IgM and IgG (acute and chronic infection), while 166 (55.3\%) cases were negative for anti DENV antibodies (Figure 2). In the present results, the DENV IgM, IgG, and both IgM and IgG seropositivity were mostly observed in male patients, $39(19.3 \%), 53(26.2 \%)$, and 14 (6.9\%), respectively, while the female patients were lower from that 10 $(10.2 \%), 15(15.3 \%)$, and $3(3.1 \%)$, respectively. Also, the statistical analysis revealed a significant association between the gender and seroprevalence of DENV IgM and DENV IgG $(P<0.05)$ (Table 2$)$. In the current work, the higher prevalence rate of DENV IgM, IgG, and both (IgM and $\operatorname{IgG}$ ) seropositivity were observed among patients aged from 21-30 years with 22 (21\%), $29(27.6 \%)$, and $8(7.6 \%)$, respectively. While the lowest from those was among (> 50) years, $2(10 \%), 3$ $(15 \%)$ and $0(0 \%)$, respectively.

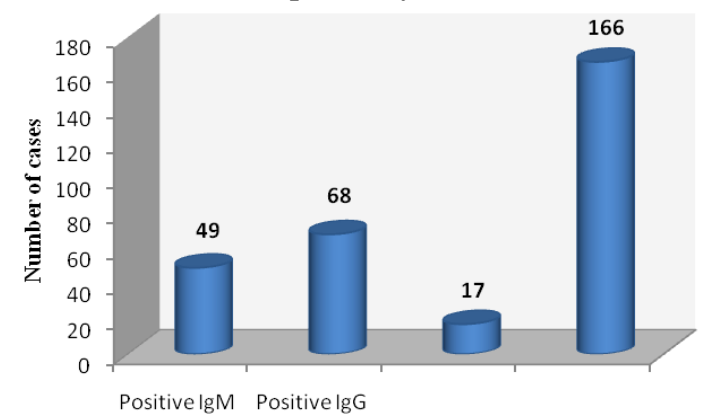

Figure 2: The positive and negative of anti DENV antibodies.

There was an association between age groups and seroprevalence of DENV was not significant $(P>0.05)$ (Table 2). The result regarding the resident area, it was found that $19.5 \%$ of positive anti-IgM, 26.2\% of positive anti-IgG, and $8.2 \%$ of positive anti-IgM and anti-IgG antibodies were reported among patients coming from the urban area. On other hand, the seropositivity of DENV antibodies among cases living in the rural area was $10.5 \%$ for $\operatorname{IgM}, 16.2 \%$ for $\operatorname{IgG}$, and $1 \%$ for both $\operatorname{IgM}$ and IgG. Also, there was a 
statistically significant association between the place of residence and seroprevalence of DENV antibodies $(P<0.05)$ (Table 2). DENV IgM, IgG, and both (IgM and $\mathrm{IgG})$ seropositive were the highest rates among participants who have secondary education level with rate $22(19.5 \%), 31(27.4 \%)$, and $7(6.2 \%)$, respectively, whereas the lowest rate was found among illiterate participants with $5(10.9 \%), 7(15.2 \%)$ and 2 (4.3\%), respectively. The result showed no significant association between any education levels and seroprevalence of DENV (P >0.05) (Table 2). Table 2 shows the highest rate of DENV seropositivity of IgM, $\mathrm{IgG}$, and both $\mathrm{IgM}$ and $\mathrm{IgG}$ antibodies were recorded among cases with low-income status when compared to the lowest seropositivity of DENV antibodies among cases with high-income status. DENV IgM, IgG, and both (IgM and $\operatorname{IgG}$ ) seropositivity cases the most effective breeding sites of mosquitoes were the bogs that were $31(19.6 \%), 42(26.6 \%)$, and $11(6.9 \%)$ of infected cases. The second source was trashes 36 $(18.2 \%), 46(23.4 \%)$ and $12(6.1 \%)$, then open drums $24(17.1 \%), 31(22.1 \%)$ and $10(7.1 \%)$, followed by, open sewage $10(16.7 \%), 13(21.7 \%)$ and $2(3.3 \%)$. Next, pools $6(13.6 \%), 9(20.5 \%)$ and $4(9.1 \%)$ respectively. The lower abundant site was tires which recorded 7 (12.5\%), $10(17.9 \%)$ and $3(5.4 \%)$, respectively of the breeding sites. There was no significant association between the seroprevalence of DENV and all breeding sites of mosquitoes $(P>0.05)$ (Table 3). In the present finding, the most of infected cases that observed positive for $\operatorname{Ig~M}, \operatorname{IgG}$, and both (IgM and $\mathrm{IgG}$ ) antibodies were recorded in Taiz city with $31(19.4 \%), 43(26.9 \%)$ and $10(6.9 \%)$, followed by Al-Barh $8(17.7 \%), 11(24.4 \%)$ and $3(6.7 \%)$, then Al-Rahedah 4 (16.7\%), 5 (20.8\%) and $2(8.3 \%)$, after that, Al-Makha $2(12.5 \%), 3(18.8 \%)$ and $1(6.2 \%)$. Next, Al-Demna 2 (10\%), $4(20 \%)$ and $1(5 \%)$, respectively, the lowest of that were Hajdah $1(10 \%)$ for $\operatorname{IgM}, 2$ (20\%) for IgG and Mawyah 1 (10\%) for IgM. While two locations were free of infection namely Al-Turbah and Al-Nashamah which no recorded any cases for $\operatorname{IgM}$ or $\operatorname{IgG}$ seropositivity (Table 4).

Table 3: Seroprevalence of DENV antibodies according to breeding sites of mosquitoes.

\begin{tabular}{|c|c|c|c|c|c|c|c|c|c|c|}
\hline \multirow{2}{*}{ Breeding sites } & \multirow{2}{*}{$\begin{array}{c}\begin{array}{c}\text { Examined } \\
\text { Cases }\end{array} \\
\text { No. (\%) }\end{array}$} & \multicolumn{3}{|c|}{ IgM positive } & \multicolumn{3}{|c|}{ IgG positive } & \multicolumn{3}{|c|}{ IgM and IgG positive } \\
\hline & & No. (\%) & $X^{2}$ & $P$-value & No. (\%) & $X^{2}$ & $P$-value & No. (\%) & $X^{2}$ & $P$-value \\
\hline Bogs & $159(53)$ & 31 (19.6) & 2.4 & 0.1 & $42(26.6)$ & 2.7 & 0.1 & $11(6.9)$ & 0.9 & 0.3 \\
\hline Open Sewage & $60(20)$ & $10(16.7)$ & 0.01 & 0.9 & $13(21.7)$ & 0.04 & 0.8 & $2(3.3)$ & 0.7 & 0.3 \\
\hline Pools & $44(14.7)$ & $6(13.6)$ & 0.3 & 0.6 & $9(20.5)$ & 0.1 & 0.7 & $4(9.1)$ & 1.2 & 0.3 \\
\hline Open drums & $140(46.7)$ & $24(17.1)$ & 0.1 & 0.7 & $31(22.1)$ & 0.04 & 0.8 & $10(7.1)$ & 1.1 & 0.3 \\
\hline Trash & $197(65.7)$ & $36(18.2)$ & 1.5 & 0.2 & $46(23.4)$ & 0.1 & 0.7 & $12(6.1)$ & 0.2 & 0.7 \\
\hline Tires & $56(18.7)$ & $7(12.5)$ & 0.7 & 0.4 & $10(17.9)$ & 0.9 & 0.3 & $3(5.4)$ & 0.01 & 0.9 \\
\hline
\end{tabular}

$\chi^{2}$ Chi-square $\geq 3.8 ; P<0.05$ (significant)

Table 4: The distribution of DENV antibodies according to sampling location.

\begin{tabular}{lcccc}
\hline \multicolumn{1}{c}{ Area } & $\begin{array}{c}\text { Participants } \\
\text { No. }(\boldsymbol{\%})\end{array}$ & $\begin{array}{c}\text { IgM positive } \\
\text { No. }(\boldsymbol{\%})\end{array}$ & $\begin{array}{c}\text { IgG positive } \\
\text { No. }(\boldsymbol{\%})\end{array}$ & $\begin{array}{c}\text { IgG and IgM positive } \\
\text { No. }(\boldsymbol{\%})\end{array}$ \\
\hline Taiz city & $160(53.4)$ & $31(19.4)$ & $43(26.9)$ & $10(6.9)$ \\
Al-Barh & $45(15)$ & $8(17.7)$ & $11(24.4)$ & $3(6.7)$ \\
Al-Rahedah & $24(8)$ & $4(16.7)$ & $5(20.8)$ & $2(8.3)$ \\
Al-Makha & $16(5.3)$ & $2(12.5)$ & $3(18.8)$ & $1(6.2)$ \\
Al-Demna & $20(6.7)$ & $2(10)$ & $4(20)$ & $1(5)$ \\
Hajdah & $10(3.3)$ & $1(10)$ & $2(20)$ & $0(0)$ \\
Mawyah & $10(3.3)$ & $1(10)$ & $0(0)$ & $0(0)$ \\
Al-Turbah & $10(3.3)$ & $0(0)$ & $0(0)$ & $0(0)$ \\
Al-Nashamah & $5(1.7)$ & $0(0)$ & $0(0)$ & $0(0)$ \\
$\quad$ Total & $300(100)$ & $49(16.3)$ & $68(22.7)$ & $17(5.7)$ \\
\hline
\end{tabular}

\section{DISCUSSION}

The findings of this study revealed that the overall seroprevalence of DENV antibodies among suspected patients was 134 cases $(44.7 \%)$. 49 cases $(16.3 \%)$ were positive for acute DENV infection (IgM positive) and $68(22.7 \%)$ of suspected cases were found positive for chronic DENV infection (IgG positive), The cases that were positive for both acute and chronic infection (IgM and IgG positive) were 17 (5.7\%), while $166(55.3 \%)$ of suspected cases were negative for dengue fever virus. Interestingly, in this study, the level of DENV chronic infection (IgG seropositivity) was found $(22.7 \%)$ more than acute infection (16.3\%) and both $(5.7 \%)$. These results were similar to a study in the Shabwah governorate by Al-Moyed et al., ${ }^{18}$ who showed that $438(53.5 \%)$ of cases were positive for
DENV antibodies. Similarly, Abdullah et al., ${ }^{19}$ found that 179 cases were positive for $\operatorname{IgM}$ antibody (42\% of all suspected specimens) and 262 cases were positive for IgG antibody (61.6\%). Also, 96 specimens were positive for both (22.5\%). However, 83(19.5\%) of suspected cases were negative for DENV antibodies.

The high prevalence of dengue IgG among suspected cases in this study may be attributed to previous exposures and endemicity of infection, especially in Taiz city, which may be evaluating the risk of complicated dengue infection through a phenomenon known as antibody-dependent improvement depending on the number of DENV serotypes that circulating in the governorate. This observation is an agreement with a study by Madani et al., ${ }^{20}$. However, the war from 
2015 until now in Yemen particularly in Taiz that lead to limited primary health care services, lack of water supply systems, sanitation services, and insufficient control on mosquitoes breeding sites facilitating the spread of endemic diseases such as dengue fever.

Furthermore, the distribution of DENV IgM, IgG, and both (IgM and $\operatorname{IgG}$ ) seropositivity in Taiz mostly observed in male cases, $(19.3 \%),(26.2 \%)$ and $(6.9 \%)$, respectively. While the female cases were lower from that $(10.2 \%),(15.3 \%)$ and $(3.1 \%)$, respectively. This result was supported with similar previous reports in different countries that noticed that the males were more affected by fever infection than females by Bin Gluth et al., ${ }^{21}$, Madani et al., ${ }^{20}$, and Abdullah et al., ${ }^{19}$ in Yemen; Ayyub et al., ${ }^{22}$ in Saudi Arabia, Abdelhalim et al., ${ }^{23}$ in Sudan. The possible reason for the high number of dengue infected cases among males due to the habit of males in the summer season, they did not cover their body whether at home or outside, spend more time outdoor and they have traveling history to that area where the dengue incidence is high. These habits make them more exposed to the bite of Aedes aegypti.

In the present study, it was revealed that the most susceptible age group for DENV infection were (2130 ) years which showed a higher prevalence of dengue infection $(\operatorname{IgM}=21 \%, \operatorname{IgG}=27.6 \%$ and both $=7.6 \%)$. While, the less infected category with dengue infection was the older people aged ( $>50$ ) years with an average $(10 \%),(15 \%)$ and $(0 \%)$ for $\operatorname{IgM}, \operatorname{IgG}$, and both, respectively. Similar observations were also reported in Yemen by Madani et al., ${ }^{20}$ and Qassim ${ }^{24}$, in India by Akula and Kammili ${ }^{25}$, and Pakistan by Muhammad et al., ${ }^{26}$. This result suggesting that the individuals in these age groups were more actively outdoor during the day which increased their chances of exposure to the infective DENV vector bite. According to the present study, the relationship between the dengue fever seropositivity and education levels which found higher in people with secondary education levels compared with lower among illiterates participants. This result is similar to a study by Abdullah et al., ${ }^{19}$ conducted in Yemen. This finding may reflect their outdoor activity during the day, for playing, schooling, or picnic that increased their chances of exposure to the infective DENV vector bite. The prevalence of dengue fever infection was noted significantly correlated with place of residence (rural or urban) areas. The prevalence rate of dengue fever infection in the urban area was more than the rural areas. This finding is in agreement with earlier studies in Yemen by Abdullah et al., ${ }^{19}$ and Bin Gluth et al., ${ }^{21}$. In the present study, the income statues were found non- significantly associated with dengue infection. But Dengue IgM, IgG and both seropositivity, were found highest with low-income statues cases (4-7 \$ daily), it was rated (18.8\%), $(25.6 \%)$ and $(6.3 \%)$, respectively. Whereas, the less infected people were with high-income statues (>20 \$ daily), which rated $(9.1 \%),(9.1 \%)$ and $(0 \%)$ for $\operatorname{IgM}$, IgG, and both, respectively. Similar results were reported byAl-Hemiree ${ }^{27}$ and Abdullah et al., ${ }^{19}$ in Yemen and by Muhammad et al., ${ }^{26}$ in Pakistan. Furthermore, in this work the dengue mosquitoes breeding sites were found positive factors related to dengue IgM, IgG, and both seropositivity. The bogs were the most breeding associated with most of the suspected cases compared to the lowest rate among the other factor such as trash, open drums, pools, open drainage and the tires. This result is an agreement with Abdullah et al., ${ }^{19}$ who noted that the highest breeding site factor was the bogs which rated $(92.2 \%)$, while the lowest factor was the tires with an average (26.3\%).

Interestingly, the distribution of dengue fever results according to districts revealed that the of the most hotspot of dengue fever virus infection in Taiz governorate was concentrated in the city of Taiz, followed by Al-Barh, Al-Rahedah, Al-Makha, AlDemna, Hajdah, and Mawyah. Whereas two districts namely Al-Turbah and Al-Nashamah were found free from DENV infection that may be due to climate change and the lack of suitable conditions for the mosquitoes breeding cycle in these areas. The low infected cases were found Al-Makha during this study that the infected case was low maybe contributing to the war most people replacement to another area within the governorate most infected case in Al-Barh which were coming from Alhodidah and Al-Makha.

\section{CONCLUSION}

In conclusion, the high prevalence of DENV antibodies in Taiz is becoming one of the most endemic governorates in Yemen which should be brought to the attention of public health authorities. Warm climate, rainfall also the war since 2015 until now contributed to destroying Yemen's healthcare, presence of breeding sites, lack of water supply systems and mosquito control measure, low-income status, and insufficient sanitation systems are the reasons that attributed to the increase of suspected cases of DENV among study area. Therefore, continuous surveillance for outbreaks of DENV infection required to identify early and in order to prevent and control the spread of infections among the community.

\section{ACKNOWLEDGEMENTS}

The authors would like to thank Laboratories and health care centers located at Taiz Governorate for their great help, also to all the team at Dar-Alsaha Modern Medical Laboratory, Taiz, Yemen and Jordanian University, Sana'a, Yemen, for their cooperation.

\section{AUTHOR'S CONTRIBUTION}

The manuscript was carried out, written, and approved in collaboration with all authors.

\section{CONFLICT OF INTEREST}

No conflict of interest associated with this work. 


\section{REFERENCES}

1. Arima Y,Chiew M, Matsui T, et al. Epidemiologic update on the dengue situation in the Western Pacific Region, 2012. Western Pac Surveill Response J 2015; 4: 47-54. https://doi.org/10.5365/WPSAR.2014.5.4.002

2. Lindenbach BD, Rice CM. Molecular biology of flaviviruses. Adv Virus Res 2003; 59: 23-61. https://doi.org/10.1016/s0065-3527(03)59002-9

3. World Health Organization (WHO). Dengue: guidelines for diagnosis, treatment, prevention and control _New ed. Geneva. World Health Organization. 2009; 1-160. PMID: 23762963

4. Smith WA, Gubler J. Geographic expansion of dengue: the impact of international travel. Med Clin North Am2008; 92(6):1377-1390.

https://doi.org/10.1016/j.mcna.2008.07.002

5. Chen LH, Wilson, ME. Dengue and Chikungunya infections in travelers. Curr Opin Infect Dis 2010; 23(5): 438-444. https://doi.org/10.1097/QCO.0b013e32833c1d16

6. Naseem S, Farheen A, Muhammad A, Fauzia R. Dengue fever outbreak in Karachi, 2005-A clinical experience. Infect Dis J 2005; 14(4):115-117.

7. Almas A, Parkash O, Akhter J. Clinical factors associated with mortality in dengue infection at a tertiary care center. Southeast Asian J Trop Med Public Health2010; 41(2): 333-340. PMID: 20578516

8. Rigau P, Clark G, Gubler D, Reiter P, Sanders E, Vorndam A. Dengue and dengue haemorrhagic fever. Lancet 1998; 352:971-977.https://doi.org/10.1016/s01406736(97)12483-7

9. Van-Kleef E, Bambrick H. The geographic distribution of dengue fever and the potential influence of global climate change. Trop IK A.net 2011;1-22. https://doi.org/10.1289/isee.2011.00337

10. Jimenez-Lucho VE, Fisher EJ, Saravolatz LD. Dengue with hemorrhagic manifestations: an imported case from the Middle East. The American J Trop Med Hyg 1984; 33(4): 650-653. https://doi.org/10.4269/ajtmh.1984.33.650

11. World Health Organization (WHO). Global strategy for dengue prevention and control 2012-2020. 20 avenues Appia, 1211 Geneva27, Switzerland. 2012. https://apps.who.int/iris/handle/10665/75303

12. Al-GaradiMA. Epidemiological review of dengue fever in Yemen.IJAR2015; 7:1578-1584

13. Alahdal M, Al-Shabi J, Ogaili M, et al. Detection of dengue fever virus serotype -4 by using one-step real-time RTPCR in Hodeidah, Yemen. BMRJ, 2016; 14(6): 1-7. https://doi.org/10.9734/BMRJ/2016/24380

14. World Health Organization (WHO). Midterm epidemiological report electronic disease early warning and response system. 2016.
15. National Information Center (NIC). About Taiz province, 2012 ,

http://www.yemenic.info/english_sitel,/Home/Aboutyemen/g overnorates/taiz/About governorates. (Accessed 30/09/2020).

16. Central Statistical Organization (CSO). Statistical year book. Central Statistical Office. Sana'a. 2013.

17. Kuno G, Gomez I, Gubler DJ. An ELISA procedure for the diagnosis of dengue infections. J Virol Methods 1991; 33: 101-113. https://doi.org/10.4269/ajtmh.1984.33.650

18. Al-Moyed T, Khaled A, Ali AJ, Aisha OJ. Sero-prevelance of reported dengue fever in Shabwah governorate, Yemen. Hadhramout J Med Sci 2012; 1:82-87. https://doi.org/10.12816/0005940

19. Abdullah QY, Ogaili M,Alahdal M, AL-Kamaran AM. Dengue fever infection in Hodeidah, Yemen: Risk factors and socioeconomic indicators. British Biomed Bull 2015; 3(1): 058-065.https://doi.org/10.3201/eid2507.180046

20. Madani TA, Abuelzein TE,Al-Bar, HS, et al. Outbreak of viral hemorrhagic fever caused by dengue virus type 3 in Al-Mukalla, Yemen. J BMC Infect Dis 2013; 13:136. https://doi.org/10.1186/1471-2334-13-136

21. Bin Ghouth AS, Amarasinghe A, Letson WG. Dengue outbreak in Hadramout, Yemen, 2010: An epidemiological perspective. Am J Trop Med Hyg2012; 86(6): 1072-1076. https://doi.org/ 10.4269/ajtmh.2012.11-0723

22. Ayyub M, Khazindar AM, Lubbad EH, et al. Characteristics of dengue fever in a large public hospital, Jeddah, Saudi Arabia. J Ayub Med Coll Abbottabad 2006; 18(2): 9-13. PMID: 16977805

23. Abdelhalim KA, Kafi SK. Seroprevalence of West Nile fever and dengue fever viruses in Suburban areas in Khartoum State, Sudan. American J Res Comm 2014; 2(8): 81-86. https://doi.org/10.1089/vbz.2017.2260

24. Qassim M. Dengue fever outbreak investigation in Taiz governorate. First national Yemen field epidemiology training program conference, 26-27 February, 2014, Sana'a, Yemen 2014; 41 https://doi.org/10.3201/eid2507.180046

25. Akula S, Kammili N. Serological and virological profile of dengue fever in a tertiary care hospital, southern part of Hyderabad, during 2011-12. Int J Microbiol 2015; 1-7. https://doi.org/10.3201/eid2507.180046

26. Muhammad, Ali R, Akbar S, Khan I, Ahmad T. Outbreak of dengue in Khwazakhela district Swat during AugustNovember 2013 Bull. Env Pharmacol Life Sci 2014; 3 (2): 26-28. https://doi.org/10.1371/journal.pone.0195706

27. Al-Hemiree AR. Epidimoligical study of dengue fever in Al-Rahedah, Taiz. MSC thesis, Department Of Medical Microbiology, Faculty Of Medicine and Health Science, Sanaa University, Yemen 2008 